\title{
Coffee consumption and risk of cardiovascular events and all-cause mortality among women with type 2 diabetes
}

\author{
W. L. Zhang • E. Lopez-Garcia • T. Y. Li • F. B. Hu • \\ R. M. van Dam
}

Received: 21 November 2008 / Accepted: 9 February 2009/Published online: 6 March 2009

(C) Springer-Verlag 2009

\begin{abstract}
Aims/hypothesis Coffee has been linked to both beneficial and harmful health effects, but data on its relationship with cardiovascular disease and mortality in patients with type 2 diabetes are sparse.

Methods This was a prospective cohort study including 7,170 women with diagnosed type 2 diabetes but free of cardiovascular disease or cancer at baseline. Coffee consumption was assessed in 1980 and then every 2-4 years using validated questionnaires. A total of 658 incident cardiovascular events (434 coronary heart disease and 224 stroke) and 734 deaths from all causes were documented between 1980 and 2004 .

Results After adjustment for age, smoking and other cardiovascular risk factors, the relative risks were 0.76 (95\% CI 0.50-1.14) for cardiovascular diseases ( $p$ trend $=$ $0.09)$ and $0.80(95 \%$ CI $0.55-1.14)$ for all-cause mortality
\end{abstract}

Electronic supplementary material The online version of this article (doi:10.1007/s00125-009-1311-1) contains supplementary material, which is available to authorised users.

W. L. Zhang • E. Lopez-Garcia • T. Y. Li • F. B. Hu •

R. M. van Dam $(\varangle)$

Department of Nutrition, Harvard School of Public Health,

665 Huntington Avenue,

Boston, MA 02115, USA

e-mail: rvandam@hsph.harvard.edu

\section{W. L. Zhang $(\bowtie)$}

Sino-German Laboratory for Molecular Medicine, FuWai

Cardiovascular Hospital and Cardiovascular Institute, Peking

Union Medical College and Chinese Academy of Medical Sciences,

Beijing 100037, China

e-mail: weilizhang@sglab.org

\section{E. Lopez-Garcia}

Universidad Autónoma de Madrid,

Madrid, Spain
( $p$ trend $=0.05$ ) for the consumption of $\geq 4$ cups/day of caffeinated coffee compared with non-drinkers. Similarly, multivariable RRs were 0.96 (95\% CI 0.66-1.38) for cardiovascular diseases $(p$ trend $=0.84)$ and $0.76(95 \%$ CI $0.54-1.07)$ for all-cause mortality $(p$ trend $=0.08)$ for the consumption of $\geq 2$ cups/day of decaffeinated coffee compared with non-drinkers. Higher decaffeinated coffee consumption was associated with lower concentrations of $\mathrm{HbA}_{1 \mathrm{c}}(6.2 \%$ for $\geq 2$ cups/day versus $6.7 \%$ for $<1 \mathrm{cup} /$ month; $p$ trend $=0.02$ ).

Conclusions These data provide evidence that habitual coffee consumption is not associated with increased risk of cardiovascular diseases or premature mortality among diabetic women.

Keywords Cardiovascular disease - Coffee consumption . Epidemiology $\cdot$ Mortality $\cdot$ Nutrition and diet

\author{
E. Lopez-Garcia \\ CIBER Epidemiologia y Salud Pública (CIBERESP), \\ Barcelona, Spain \\ URL: www.ciberesp.es
}

\section{F. B. $\mathrm{Hu}$}

Department of Epidemiology, Harvard School of Public Health, Boston, MA, USA

F. B. Hu $\cdot$ R. M. van Dam

Channing Laboratory, Brigham

and Women's Hospital and Harvard Medical School,

Boston, MA, USA 


\section{Abbreviations \\ CVD Cardiovascular disease \\ MI Myocardial infarction \\ NHS Nurses' Health Study}

\section{Introduction}

Type 2 diabetes mellitus increases the risk of cardiovascular disease (CVD) and mortality two- to fourfold [1]. Moreover, diabetes increases the risk of CVD to a greater extent in women compared with men, and diabetes may eliminate women's protection against coronary heart disease [2].

Coffee drinking is widespread across the world; more than $50 \%$ of Americans drink coffee, and the average per capita intake is about two cups per day [3]. Thus, even small health effects of coffee could have a large impact on public health. Habitual coffee consumption has been associated with better glucose tolerance in persons without diabetes [4]. In addition, coffee contains phenolic compounds with antioxidant properties [5], and may affect the process of atherosclerosis favourably by preventing oxidation of LDL-cholesterol [6] and inhibiting platelet aggregation and thrombogenesis [7,8]. On the other hand, caffeine intake acutely raises blood pressure [9, 10], homocysteine levels [11] and postprandial glucose levels [12] in short-term trials. Because of these complex physiological effects of coffee and because at least partial tolerance of the haemodynamic effects of caffeine typically develop with long-term use [13], it is difficult to extrapolate findings from short-term metabolic studies to the effects of long-term use of coffee.

The relationship between coffee consumption and CVD and mortality remains controversial $[14,15]$. While most recent prospective studies have suggested that coffee consumption is not associated with an increased risk of coronary heart disease and mortality in the general population [16-20], data on diabetic patients are sparse [21]. Therefore, we prospectively examined the relationship between coffee consumption and the incidence of coronary heart disease and stroke and all-cause mortality among women with type 2 diabetes in the Nurses' Health Study (NHS).

\section{Methods}

Study population The NHS cohort was established in 1976 when 121,700 female registered nurses, 30-55 years old and residing in 11 large US states, completed a postal questionnaire about their medical history and lifestyle. The present study included the 7,170 women who reported physician-diagnosed type 2 diabetes on any questionnaire between 1976 and 2004 (1,552 prevalent diabetic women in 1980 and 5,618 incident diabetic women during the followup). Women with diabetes diagnosed before the age of 30 years, or with a history of CHD (including myocardial infarction [MI], angina, and/or coronary revascularisation), stroke or cancer reported on the 1980 questionnaire (when diet was first assessed) or before, were excluded at baseline. This study was approved by the institutional review board at Brigham and Women's Hospital and return of the questionnaires was assumed to imply informed consent.

Confirmation of diabetes mellitus A supplementary questionnaire was mailed to women who indicated on any biennial questionnaire that they had been diagnosed as having diabetes. Consistent with the criteria of the National Diabetes Data Group [22], diagnosed cases required (1) an elevated glucose concentration (fasting plasma glucose $\geq 7.8 \mathrm{mmol} / 1$, random plasma glucose $\geq 11.1 \mathrm{mmol} / 1$ or plasma glucose $\geq 11.1 \mathrm{mmol} / 1$ after an oral glucose load) and at least one symptom related to diabetes (excessive thirst, polyuria, weight loss or hunger); (2) no symptoms but elevated glucose concentrations on two occasions; and (3) treatment with insulin or oral hypoglycaemic medication. For cases of type 2 diabetes identified after 1998, the cut-off point used for fasting plasma glucose concentrations was lowered to $7.0 \mathrm{mmol} / \mathrm{l}$ according to the American Diabetes Association criteria [23]. Our validation study showed a high level of confirmation (98\%) of self-reported type 2 diabetes [24].

Assessment of coffee consumption Dietary questionnaires were sent to the NHS participants in 1980, 1984, 1986, 1990, 1994, 1998 and 2002. On each questionnaire, participants were asked how often on average during the previous year they had consumed coffee and tea. Decaffeinated coffee and different types of caffeinated soft drinks were first assessed in 1984. We also assessed total caffeine intake as described previously [25]. In our validation study, we obtained high correlations between consumption of coffee and other caffeinated beverages estimated from the food frequency questionnaire and consumption estimated from repeated 1-week diet records (coffee, $r=0.78$; tea, $r=$ 0.93; and caffeinated sodas, $r=0.85$ ) [26].

Ascertainment of endpoints The endpoints were incident CHD (defined as non-fatal MI or fatal CHD), stroke and all-cause mortality. We requested permission to review the medical records of women who reported having a non-fatal MI or stroke on a follow-up questionnaire. MI was confirmed if it met the criteria of the World Health Organization of symptoms and the patient's records showed diagnostic electrocardiographic changes or elevated cardiac enzyme levels [27]. Fatal CHD was defined as fatal MI if 
this was confirmed by hospital records or autopsy, or if coronary disease was listed as the cause of death on the certificate. Sudden death within $1 \mathrm{~h}$ of onset of symptoms in women with no other plausible cause other than coronary disease was also included. Stroke was confirmed by medical records according to the criteria of the National Survey of Stroke [28], which define it as a constellation of neurological deficits, sudden or rapid in onset, lasting at least $24 \mathrm{~h}$ or until death.

Deaths were reported by next of kin or the postal system or ascertained through the National Death Index. Follow-up for the death was more than $98 \%$ complete [29]. We obtained copies of death certificates and medical records and determined causes of death (classified according to the categories of the International Classification of Diseases, Ninth Revision [ICD-9; www.cdc.gov/nchs/about/major/ dvs/icd9des.htm, accessed 15 February 2009]).

Laboratory methods Blood was drawn in 1989-1990. Concentrations of $\mathrm{HbA}_{1 \mathrm{c}}$ were based on turbidimetric immunoinhibition with haemolysed whole blood or packed red cells with a CV of less than $3.0 \%$. The concentrations of total cholesterol, HDL-cholesterol and triacylglycerol were measured simultaneously on a Hitachi 911 analyser (Roche Diagnostics, Indianapolis, IN, USA); the CVs for these measurements were less than $1.8 \%$. Concentrations of LDL-cholesterol were measured using a homogeneous direct method (Genzyme, Cambridge, MA, USA) with a CV of less than 3.1\%. Concentrations of apolipoprotein B100 were measured in an immunonephelometric assay (Wako Chemicals, Richmond, VA, USA) with a CV of less than $5.0 \%$.

Statistical analysis The follow-up period started at the date of return of the questionnaire on which type 2 diabetes diagnosis was first reported and lasted until the occurrence of CHD, stroke, death or the end of the study period (1 June 2004). Women who reported having cardiovascular disease on previous questionnaires were excluded from subsequent follow-up.

Cox proportional hazards regression was used to investigate the association of coffee consumption with the incidence of CVD events and all-cause mortality. Multivariable models were first adjusted for age and smoking status. Furthermore, we adjusted for BMI, physical activity, alcohol intake, use of hormone therapy for women, parental history of MI, history of hypertension and hypercholesterolaemia, duration of diabetes, insulin or other hypoglycaemic therapy, total energy intake, and the use of multivitamin and vitamin E supplements. An additional analysis was further adjusted for dietary factors. The median value of each category of coffee consumption was used as a continuous variable to test for linear trends.
To represent the long-term intake of coffee and to reduce measurement error, we conducted analyses using cumulative updated coffee intake from all available dietary questionnaires up to the start of each 2 year follow-up interval [30]. To determine whether there were different effects of long-term and short-term effects of coffee consumption, we also used the most recent report of coffee intake in relation to the incidence of CVD events. In addition, we studied the association of caffeine intake, decaffeinated coffee and tea consumption with CVD risk.

As a complementary study, we examined the association of caffeinated and decaffeinated coffee with plasma concentrations of lipids and $\mathrm{HbA}_{1 \mathrm{c}}$ by conducting a crosssectional analysis in the subgroup including 663 diabetic women who provided blood samples in 1989-1990 and had a confirmed diagnosis of type 2 diabetes mellitus but not of cardiovascular disease or cancer [31]. There was no substantial difference between the total group and the subsample in coffee consumption and baseline characteristics. We used dietary information from the 1990 food frequency questionnaire. Multivariable-adjusted geometric means $(95 \% \mathrm{CI})$ of plasma lipids and $\mathrm{HbA}_{1 \mathrm{c}}$ across categories of coffee consumption were calculated. All analyses were performed with SAS software, version 8.2 (SAS Institute, Cary, NC, USA). The authors had full access to the data and take responsibility for its integrity. All authors have approved the manuscript as written.

\section{Results}

Between 1980 and 2004 (62,722 person-years of followup), we documented 658 incident cases of cardiovascular disease (434 cases of CHD and 224 of stroke) and 734 deaths from all causes (282 from CHD or stroke, 182 from cancer and 270 from other causes). Higher coffee consumption was strongly associated with cigarette smoking and alcohol use (Table 1).

In both age- and smoking-adjusted analyses and multivariable analyses adjusting for cardiovascular risk factors, we found no significant association between long-term caffeinated coffee consumption and the risk of $\mathrm{CHD}$ or stroke (Table 2). Further adjustment for other dietary factors, suggested a tendency to an inverse association between coffee consumption and the risk of CHD ( $p$ for trend=0.06), particularly fatal CHD ( $p$ for trend=0.07). A sensitivity analysis adjusting for tea, sugar-sweetened soft drinks and dairy food intake did not substantially change the results. Additional analyses also showed no direct association between coffee consumption and CVD risk in any subgroup stratified by risk factor status, including obesity, smoking status and duration of diabetes (see Electronic supplementary material [ESM] Table 1). 
Table 1 Baseline characteristics according to caffeinated coffee consumption among women with type 2 diabetes $(n=7,170)$

\begin{tabular}{|c|c|c|c|c|c|c|}
\hline \multirow[t]{2}{*}{ Variables } & \multicolumn{6}{|c|}{ Caffeinated coffee consumption (cups) } \\
\hline & $<1 /$ month & $1 /$ month to $4 /$ week & $5-7 /$ week & 2-3/day & $\geq 4$ /day & $p$ value for trend \\
\hline Participants $(n)$ & 1,451 & 1,076 & 2,302 & 1,717 & 624 & \\
\hline Age (years) & 48 & 48 & 49 & 49 & 48 & 0.26 \\
\hline \multicolumn{7}{|l|}{ Risk factors } \\
\hline BMI $\left(\mathrm{kg} / \mathrm{m}^{2}\right)$ & 29.9 & 30.7 & 30.2 & 29.5 & 28.4 & 0.12 \\
\hline Current smokers (\%) & 11 & 8 & 12 & 20 & 39 & $<0.001$ \\
\hline History of hypertension (\%) & 42 & 51 & 46 & 40 & 37 & 0.11 \\
\hline History of hypercholesterolaemia (\%) & 36 & 43 & 40 & 34 & 29 & 0.15 \\
\hline Parental history of MI (\%) & 22 & 22 & 24 & 22 & 22 & 0.87 \\
\hline Postmenopausal hormone use (\%) & 20 & 24 & 21 & 17 & 13 & 0.74 \\
\hline Aspirin use $(\%)^{\mathrm{a}}$ & 15 & 16 & 18 & 16 & 16 & 0.67 \\
\hline Physical activity (h/week) & 2.4 & 2.2 & 2.1 & 2.2 & 2.4 & 0.36 \\
\hline Alcohol (g/day) & 2.4 & 2.8 & 4.2 & 5.2 & 4.8 & 0.005 \\
\hline \multicolumn{7}{|l|}{ Dietary daily intake } \\
\hline Saturated fat (\% energy) & 13.5 & 12.9 & 13.2 & 14.0 & 14.9 & 0.13 \\
\hline Polyunsaturated fat (\% energy) & 5.6 & 5.8 & 5.8 & 5.7 & 5.7 & 0.56 \\
\hline Trans fat (\% energy) & 1.9 & 1.9 & 2.0 & 2.0 & 2.2 & 0.10 \\
\hline Total $n-3$ fatty acids ( $\%$ energy) & 0.61 & 0.63 & 0.64 & 0.63 & 0.61 & 0.75 \\
\hline Cereal fibre (g/day) & 3.3 & 3.7 & 3.5 & 3.3 & 3.0 & 0.39 \\
\hline Folate ( $\mu \mathrm{g} /$ day) & 404.8 & 397.9 & 387.7 & 369.6 & 344.3 & 0.03 \\
\hline Glycaemic load & 98.8 & 99.6 & 95.8 & 90.3 & 85.4 & 0.002 \\
\hline Caffeine, mg/day & 101.7 & 139.3 & 269.2 & 467.1 & 775.8 & $<0.001$ \\
\hline Sugar-sweetened soft drinks (servings/day) & 1.1 & 1.0 & 1.2 & 0.9 & 1.0 & 0.10 \\
\hline Dairy (servings/day) & 2.0 & 2.6 & 2.9 & 3.5 & 3.9 & 0.007 \\
\hline Tea (cups/day) & 1.1 & 0.9 & 0.7 & 0.6 & 0.5 & 0.01 \\
\hline \multicolumn{7}{|l|}{ Supplements } \\
\hline Multivitamins (\%) & 37 & 42 & 41 & 37 & 29 & 0.02 \\
\hline Vitamin E (\%) & 25 & 31 & 30 & 23 & 17 & 0.01 \\
\hline
\end{tabular}

Values are means unless otherwise indicated

Data were from different periods based on the time of diagnosis of type 2 diabetes during follow-up (1980-2004)

${ }^{a}$ Aspirin use denotes 1 or more times per week

Compared with coffee intake of less than 1 cup/month, caffeinated coffee consumption of 4 cups/day or more appeared to be associated with a slightly lower risk of allcause mortality after adjustment for cardiovascular risk factors, lifestyle and dietary factors (RR, $0.80 ; 95 \% \mathrm{CI}$, $0.55-1.14 ; p$ for trend $=0.05$; Table 2 ). This was due to an inverse association between coffee and cardiovascular death (RR, 0.62; 95\% CI, 0.33-1.17; $p$ for trend $=0.01$ ). Coffee consumption was not associated with non-cardiovascular death $(\mathrm{RR}, 0.94 ; 95 \% \mathrm{CI}, 0.60-1.46 ; p$ for trend $=0.70)$. We conducted a sensitivity analysis in which we updated coffee consumption using the most recent data in relation to CVD risk and mortality; this yielded very similar results (results not shown).
We also examined caffeine intake in relation to the risk of CVD and all-cause mortality and did not observe significant associations. The multivariable adjusted RRs $(95 \% \mathrm{CI})$ for quintiles of caffeine intake were 1.0, 1.11 (0.74-1.69), $0.98(0.51-1.80), 1.09(0.71-1.66)$ and 0.90 $(0.70-1.15)(p$ for trend $=0.73)$ for cardiovascular diseases, and 1.0, $0.93(0.63-1.38), 0.71(0.39-1.32), 1.25$ (0.84$1.86)$ and $0.96(0.76-1.23)$ ( $p$ for trend $=0.36)$ for all-cause mortality. Decaffeinated coffee consumption tended to be associated with a lower risk of all-cause mortality, but this association was not significant. No substantial associations were observed for tea (see ESM Table 2).

In a cross-sectional analysis for a biomarker, higher decaffeinated coffee consumption was associated with 
Table 2 Relative risks (95\% CI) of cardiovascular diseases and all-cause mortality by caffeinated coffee consumption among women with type 2 diabetes $(1980-2004)^{\mathrm{a}}$

\begin{tabular}{|c|c|c|c|c|c|c|}
\hline \multirow[t]{2}{*}{ Variables } & \multicolumn{6}{|c|}{ Caffeinated coffee consumption (cups) } \\
\hline & $<1 /$ month & $1 /$ month to $4 /$ week & $5-7 /$ week & $2-3 /$ day & $\geq 4 /$ day & $p$ for trend \\
\hline \multicolumn{7}{|l|}{ Total cardiovascular events } \\
\hline Person years & 12,262 & 10,853 & 21,351 & 13,754 & 4,504 & \\
\hline Cases $(n)$ & 114 & 114 & 261 & 131 & 38 & \\
\hline Age- and smoking-adjusted & 1.0 & $0.97(0.75-1.26)$ & $1.05(0.84-1.31)$ & $0.86(0.66-1.10)$ & $0.82(0.56-1.19)$ & 0.11 \\
\hline Multivariable $\mathrm{I}^{\mathrm{b}}$ & 1.0 & $1.02(0.79-1.33)$ & $1.14(0.91-1.43)$ & $0.94(0.73-1.23)$ & $0.82(0.55-1.21)$ & 0.18 \\
\hline Multivariable II $^{\mathrm{c}}$ & 1.0 & $1.04(0.80-1.36)$ & $1.14(0.91-1.44)$ & $0.92(0.70-1.20)$ & $0.76(0.50-1.14)$ & 0.09 \\
\hline \multicolumn{7}{|l|}{ Total coronary heart disease } \\
\hline Cases $(n)$ & 77 & 69 & 178 & 82 & 28 & \\
\hline Age- and smoking-adjusted & 1.0 & $0.89(0.64-1.23)$ & $1.07(0.82-1.41)$ & $0.78(0.57-1.07)$ & $0.85(0.55-1.33)$ & 0.19 \\
\hline Multivariable $\mathrm{I}^{\mathrm{b}}$ & 1.0 & $0.91(0.65-1.26)$ & $1.13(0.86-1.50)$ & $0.83(0.60-1.15)$ & $0.79(0.50-1.26)$ & 0.16 \\
\hline Multivariable $\mathrm{II}^{\mathrm{c}}$ & 1.0 & $0.94(0.67-1.30)$ & $1.14(0.86-1.50)$ & $0.80(0.57-1.12)$ & $0.70(0.43-1.14)$ & 0.06 \\
\hline \multicolumn{7}{|l|}{ Non-fatal MI } \\
\hline Cases $(n)$ & 41 & 25 & 99 & 37 & 15 & \\
\hline Age- and smoking-adjusted & 1.0 & $0.61(0.37-1.02)$ & $1.15(0.79-1.67)$ & $0.66(0.42-1.04)$ & $0.80(0.43-1.48)$ & 0.31 \\
\hline Multivariable $\mathrm{I}^{\mathrm{b}}$ & 1.0 & $0.60(0.36-0.99)$ & $1.15(0.79-1.68)$ & $0.70(0.44-1.11)$ & $0.77(0.41-1.47)$ & 0.40 \\
\hline Multivariable II $^{\mathrm{c}}$ & 1.0 & $0.60(0.36-1.00)$ & $1.16(0.79-1.70)$ & $0.69(0.43-1.13)$ & $0.74(0.38-1.45)$ & 0.38 \\
\hline \multicolumn{7}{|l|}{ Fatal CHD } \\
\hline Cases $(n)$ & 36 & 44 & 79 & 45 & 13 & \\
\hline Age- and smoking-adjusted & 1.0 & $1.18(0.76-1.84)$ & $0.99(0.66-1.48)$ & $0.92(0.59-1.43)$ & $0.91(0.47-1.74)$ & 0.38 \\
\hline Multivariable $\mathrm{I}^{\mathrm{b}}$ & 1.0 & $1.31(0.83-2.04)$ & $1.11(0.74-1.67)$ & $0.99(0.63-1.57)$ & $0.82(0.42-1.60)$ & 0.26 \\
\hline Multivariable IIc & 1.0 & $1.41(0.90-2.22)$ & $1.12(0.74-1.69)$ & $0.91(0.56-1.46)$ & $0.67(0.33-1.36)$ & 0.07 \\
\hline \multicolumn{7}{|l|}{ Stroke } \\
\hline Cases $(n)$ & 37 & 45 & 83 & 49 & 10 & \\
\hline Age- and smoking-adjusted & 1.0 & $1.14(0.74-0.77)$ & $1.01(0.68-1.49)$ & $1.02(0.66-1.57)$ & $0.73(0.36-1.50)$ & 0.37 \\
\hline Multivariable $\mathrm{I}^{\mathrm{b}}$ & 1.0 & $1.24(0.80-1.93)$ & $1.14(0.77-1.71)$ & $1.19(0.76-1.86)$ & $0.85(0.41-1.77)$ & 0.75 \\
\hline Multivariable $\mathrm{II}^{\mathrm{c}}$ & 1.0 & $1.24(0.80-1.93)$ & $1.13(0.76-1.70)$ & $1.16(0.73-1.85)$ & $0.86(0.40-1.84)$ & 0.74 \\
\hline \multicolumn{7}{|l|}{ All-cause mortality } \\
\hline Person years & 12,342 & 10,911 & 21,506 & 13,841 & 4,526 & \\
\hline Deaths $(n)$ & 136 & 135 & 267 & 146 & 50 & \\
\hline Age- and smoking-adjusted & 1.0 & $0.92(0.73-1.17)$ & $0.86(0.70-1.06)$ & $0.78(0.62-0.99)$ & $0.92(0.66-1.28)$ & 0.22 \\
\hline Multivariable $\mathrm{I}^{\mathrm{b}}$ & 1.0 & $1.08(0.85-1.38)$ & $1.04(0.84-1.28)$ & $0.89(0.70-1.13)$ & $0.82(0.59-1.15)$ & 0.06 \\
\hline Multivariable II $^{\mathrm{c}}$ & 1.0 & $1.10(0.86-1.40)$ & $1.04(0.84-1.30)$ & $0.87(0.67-1.12)$ & $0.80(0.55-1.14)$ & 0.05 \\
\hline
\end{tabular}

\footnotetext{
${ }^{\mathrm{a}}$ Total coronary heart disease includes non-fatal MI and fatal CHD; total cardiovascular events include total coronary heart disease and stroke

${ }^{\mathrm{b}}$ Adjusted for age (5-year categories), smoking status (never, past and current 1-14, 15-24 or $\geq 25$ cigarettes/day), BMI (<23.0, 23.0-24.9, 25.0$27.9,28.0-29.9$ or $\left.\geq 30.0 \mathrm{~kg} / \mathrm{m}^{2}\right)$, alcohol intake $(0,0.1-4.9,5-14$ or $\geq 15 \mathrm{~g} /$ day), parental history of MI, history of hypertension, hypercholesterolaemia, menopausal status and use of hormone therapy, physical activity $(<1,1-1.9,2-3.9,4-6.9 \mathrm{or} \geq 7 \mathrm{~h} /$ week $)$, multivitamin use and vitamin $E$ supplement use, total energy intake, duration of diabetes $(<5,5-10,11-15$ or $\geq 15$ years $)$ and hypoglycaemic medication ${ }^{\mathrm{c}}$ Adjusted for factors cited above and polyunsaturated, saturated and trans fat, $n-3$ fatty acids, glycaemic load, dietary cereal fibre and folate intake (all in quintiles)
}

lower concentrations of $\mathrm{HbA}_{1 \mathrm{c}}(6.2 \%$ for $\geq 2$ cups/day versus $6.7 \%$ for $<1 \mathrm{cup} / \mathrm{month}$; $p$ for trend=0.02). Neither caffeinated nor decaffeinated coffee was associated with blood lipid levels, including total cholesterol, LDLcholesterol and HDL-cholesterol, apolipoprotein B-100 and triacylglycerol (Table 3).

\section{Discussion}

In this prospective study in diabetic women, higher coffee consumption was not associated with a higher risk of cardiovascular diseases or all-cause mortality. Higher decaffeinated, but not caffeinated, coffee consumption was 
Table 3 Cross-sectional analysis of the relationship between coffee and plasma concentrations of lipids and $\mathrm{HbA}_{1 \mathrm{c}}$ among diabetic women $(n=663)$

\begin{tabular}{|c|c|c|c|c|c|c|c|}
\hline $\begin{array}{l}\text { Beverage } \\
\text { consumption (cups) }\end{array}$ & $n$ & $\mathrm{HbA}_{1 \mathrm{c}}(\%)^{\mathrm{a}}$ & $\begin{array}{l}\text { Total cholesterol } \\
(\mathrm{mmol} / \mathrm{l})\end{array}$ & $\begin{array}{l}\text { HDL-cholesterol } \\
(\mathrm{mmol} / \mathrm{l})\end{array}$ & $\begin{array}{l}\text { LDL-cholesterol } \\
(\mathrm{mmol} / \mathrm{l})^{\mathrm{b}}\end{array}$ & $\begin{array}{l}\text { Apolipoprotein } \\
\text { B-100 (g/l) }\end{array}$ & $\begin{array}{l}\text { Triacylglycerol } \\
(\mathrm{mmol} / \mathrm{l})\end{array}$ \\
\hline \multicolumn{8}{|l|}{ Caffeinated coffee } \\
\hline$<1 /$ month & 174 & $6.5(6.3-6.7)$ & $5.88(5.72-6.05)$ & $1.30(1.25-1.35)$ & $3.50(3.35-3.66)$ & $1.03(0.99-1.07)$ & $2.02(1.86-2.19)$ \\
\hline $1 /$ month to $4 /$ week & 140 & $6.6(6.3-6.8)$ & $5.85(5.67-6.04)$ & $1.24(1.18-1.30)$ & $3.51(3.35-3.69)$ & $1.02(0.98-1.06)$ & $2.12(1.94-2.33)$ \\
\hline $5-7 /$ week & 251 & $6.7(6.5-6.9)$ & $5.80(5.66-5.94)$ & $1.22(1.18-1.26)$ & $3.53(3.41-3.66)$ & $1.03(0.10-1.06)$ & $2.04(1.90-2.36)$ \\
\hline$\geq 2 /$ day & 98 & $6.3(6.0-6.6)$ & $5.89(5.67-6.11)$ & $1.21(1.14-1.27)$ & $3.64(3.44-3.86)$ & $1.04(0.99-1.09)$ & $2.11(1.90-2.36)$ \\
\hline$p$ value for linear trend ${ }^{\mathrm{c}}$ & & 0.52 & 0.98 & 0.18 & 0.46 & 0.88 & 0.83 \\
\hline \multicolumn{8}{|l|}{ Decaffeinated coffee } \\
\hline$<1 /$ month & 252 & $6.7(6.5-6.9)$ & $5.87(5.73-6.01)$ & $1.25(1.21-1.29)$ & $3.59(3.46-3.72)$ & $1.03(1.00-1.06)$ & $2.05(1.92-2.19)$ \\
\hline $1 /$ month to $4 /$ week & 214 & $6.5(6.3-6.7)$ & $5.87(5.73-6.02)$ & $1.20(1.16-1.24)$ & $3.56(3.42-3.70)$ & $1.05(1.01-1.08)$ & $2.14(1.99-2.30)$ \\
\hline $5-7 /$ week & 149 & $6.5(6.3-6.8)$ & $5.85(5.67-6.03)$ & $1.30(1.24-1.35)$ & $3.45(3.29-3.61)$ & $1.01(0.97-1.05)$ & $2.03(1.86-2.21)$ \\
\hline$\geq 2 /$ day & 48 & $6.2(5.8-6.6)$ & $5.58(5.29-5.89)$ & $1.26(1.17-1.36)$ & $3.45(3.18-3.75)$ & $0.98(0.92-1.05)$ & $1.89(1.61-2.20)$ \\
\hline$p$ value for linear trend ${ }^{\mathrm{c}}$ & & 0.02 & 0.40 & 0.08 & 0.52 & 0.15 & 0.21 \\
\hline
\end{tabular}

A cross-sectional analysis was conducted in the subgroup including 663 women who provided blood sample in 1989-1990 and had a confirmed diagnosis of type 2 diabetes mellitus but not of cardiovascular disease. Adjusted geometric mean (95\% CI) plasma concentrations of lipids and $\mathrm{HbA}_{1 \mathrm{c}}$ were calculated using multiple linear regression models (in PROC GLM) controlling for age (5 year categories), smoking status (never, past and current $1-14,15-24$ or $\geq 25$ cigarettes/day), BMI $\left(<23.0,23.0-24.9,25.0-27.9,28.0-29.9\right.$ or $\left.\geq 30.0 \mathrm{~kg} / \mathrm{m}^{2}\right)$, alcohol intake $(0,0.1-4.9$, $5-14$ or $\geq 15 \mathrm{~g}$ /day), physical activity $(<1,1-1.9,2-3.9,4-6.9$ or $\geq 7 \mathrm{~h} /$ week $)$, menopausal status and use of hormone therapy, and aspirin use in 1990 To convert the values for serum cholesterol, apolipoprotein B-100 and triacylglycerol to $\mathrm{mg} / \mathrm{dl}$, divide by $0.0259,0.01$ and 0.0113 , respectively ${ }^{\mathrm{a}}$ Data on $\mathrm{HbA}_{1 \mathrm{c}}$ were missing for 12 women

${ }^{\mathrm{b}}$ Data on LDL-cholesterol were missing for three women

${ }^{\mathrm{c}}$ From multiple linear regression models for the relationship between beverage consumption (cups/day) and log-transformed markers

associated with lower $\mathrm{HbA}_{1 \mathrm{c}}$ levels. Neither caffeinated nor decaffeinated coffee consumption was associated with blood lipid levels.

The strengths of the study included the large number of diabetic women, the prospective design and the long follow-up period. Also, we controlled for severity of diabetes by adjusting for duration of diabetes and hypoglycaemic medications. The food frequency questionnaire that we used in the dietary assessment has been evaluated previously as a reasonable reflection of long-term diet [32]. We reduced error by measuring coffee consumption repeatedly during the follow-up. Because coffee drinking is often thought to be an unhealthy habit, people may reduce the consumption of coffee after developing a disease. These changes in coffee habits would dilute a possible positive association between coffee and CVD risk. To reduce bias from this source, we excluded women with hypertension, hypercholesterolaemia or cardiovascular diseases at baseline. We used coffee consumption after the diagnosis of diabetes, thus incorporating possible changes in intake as a result of the diagnosis. Different brewing strengths may have led to some misclassification of coffee intake; nevertheless, we could study a large contrast in coffee intake ( $\geq 4$ cups per day versus none) that will remain large even in the presence of variation in brew strength.
Type 2 diabetes is characterised by insulin resistance, lipid metabolism abnormalities, increased platelet aggregation and clotting, and high oxidative stress, all of which are associated with accelerated incidence of cardiovascular disease [33]. A growing body of evidence shows that coffee intake may favourably affect the process of atherosclerosis by reducing the oxidation of LDLcholesterol [6], inhibiting platelet aggregation and thrombogenesis $[7,8]$ and preventing inflammation and endothelial dysfunction [31]. In randomised trials, the consumption of unfiltered coffee, such as boiled or French Press coffee, increased serum LDL-cholesterol concentrations, whereas paper-filtered coffee did not have substantial effects on cholesterol concentrations [34]. In our cohort, women predominantly consumed paper-filtered coffee [19] and the lack of association between coffee consumption and blood lipid levels is thus consistent with the findings of randomised trials.

Coffee contains various components that may improve glucose metabolism [35, 36]. The phenol chlorogenic acid has been shown to reduce glucose concentrations in rats [37] and may stimulate secretion of glucagon-like peptide-1 [38]. Glucagon-like peptide-1 is well known for its beneficial effects on glucose-induced insulin secretion and insulin action [39]. These mechanisms may explain our 
finding that higher decaffeinated coffee consumption was associated with lower $\mathrm{HbA}_{1 \mathrm{c}}$ levels, a marker of glycaemic control. The results of this cross-sectional analysis should be interpreted with caution, because 'reverse causation'better-treated and more health-concerned participants switching to decaffeinated coffee-may have biased the results. Longer-term trials of caffeinated, decaffeinated coffee and glycaemic control in diabetic patients are needed.

Concerns have been raised that caffeine acutely increases blood pressure [40] and plasma homocysteine concentrations [41]. However, the results of prospective cohort studies suggest that long-term coffee consumption is not substantially associated with a risk of hypertension [42]. The detrimental short-term effects of caffeine intake on blood pressure may be reduced by the development of partial tolerance with long-term use and the counteracting effects of other coffee components [43]. In contrast, the effects of coffee on homocysteine appear to remain after long-term consumption [44]. It is unclear, however, whether homocysteine has a causal effect on the development of CHD or is merely an innocent bystander [45].

Coffee consumption was correlated with smoking in this study, consistent with observations in other study populations [21, 46]. However, we did not find an interaction between smoking and coffee in relation to CVD risk. Our study showed a modest inverse association of coffee consumption with CVD incidence and mortality, although this was only of borderline significance. This inverse association was more clearly observed in a previous study in Finnish persons with diabetes [21].

In conclusion, our findings in this large prospective study do not support the hypothesis that habitual consumption of caffeinated coffee increases the risk of cardiovascular events and mortality among persons with type 2 diabetes. Further research should evaluate whether the consumption of decaffeinated coffee may improve glycaemic control.

Acknowledgements This study was supported by grants CA87969, HL60712, HL34594 and DK58845 from the National Institutes of Health. The research of W. L. Zhang is supported by grant 30670862 from the National Natural Science Foundation of China and that of E. Lopez-Garcia is supported by a Ramón y Cajal contract.

Duality of interest The authors declare that there is no duality of interest associated with this manuscript.

\section{References}

1. Wilson PWF, Kannel WB (1992) Epidemiology of hyperglycemia and atherosclerosis. In: Ruderman N, Williamson J, Brownlee M (eds) Hyperglycemia, diabetes, and vascular disease. Oxford University Press, New York, pp 21-29
2. DeStefano F, Ford ES, Newman J et al (1993) Risk factors for coronary heart disease mortality among persons with diabetes. Ann Epidemiol 3:27-34

3. Lundsberg LS (1998) Caffeine consumption. In: Spiller GA (ed) Caffeine. CRC, Boca Raton, FL, pp 199-224

4. Bidel S, Hu G, Sundvall J, Kaprio J, Tuomilehto J (2006) Effects of coffee consumption on glucose tolerance, serum glucose and insulin levels - a cross-sectional analysis. Horm Metab Res 38:38-43

5. Bonita JS, Mandarano M, Shuta D, Vinson J (2007) Coffee and cardiovascular disease: in vitro, cellular, animal, and human studies. Pharmacol Res 55:187-198

6. Yukawa GS, Mune M, Otani H et al (2004) Effects of coffee consumption on oxidative susceptibility of low-density lipoproteins and serum lipid levels in humans. Biochemistry (Mosc) 69:70-74

7. Bydlowski SP, Yunker RL, Rymaszewski Z, Subbiah MT (1987) Coffee extracts inhibit platelet aggregation in vivo and in vitro. Int J Vitam Nutr Res 57:217-223

8. Natella F, Nardini M, Belelli F et al (2008) Effect of coffee drinking on platelets: inhibition of aggregation and phenols incorporation. Br J Nutr 100:1276-1282

9. Jee SH, He J, Whelton PK, Suh I, Klag MJ (1999) The effect of chronic coffee drinking on blood pressure: a meta-analysis of controlled clinical trials. Hypertension 33:647-652

10. Hartley TR, Lovallo WR, Whitsett TL (2004) Cardiovascular effects of caffeine in men and women. Am J Cardiol 93:1022-1026

11. Verhoef P, Pasman WJ, van Vliet T, Urgert R, Katan MB (2002) Contribution of caffeine to the homocysteine-raising effect of coffee: a randomized controlled trial in humans. Am J Clin Nutr 76:1244-1248

12. Lane JD, Feinglos MN, Surwit RS (2008) Caffeine increases ambulatory glucose and postprandial responses in coffee drinkers with type 2 diabetes. Diabetes Care 31:221-222

13. Robertson D, Wade D, Workman R, Woosley RL, Oates JA (1981) Tolerance to the humoral and hemodynamic effects of caffeine in man. J Clin Invest 67:1111-1117

14. Greenland S (1993) A meta-analysis of coffee, myocardial infarction, and coronary death. Epidemiology 4:366-374

15. Sofi F, Conti AA, Gori AM et al (2007) Coffee consumption and risk of coronary heart disease: a meta-analysis. Nutr Metab Cardiovasc Dis 17:209-223

16. Myers MG, Basinski A (1992) Coffee and coronary heart disease. Arch Intern Med 152:1767-1772

17. Stensvold I, Tverdal A, Jacobsen BK (1996) Cohort study of coffee intake and death from coronary heart disease over 12 years. BMJ 312:544-545

18. Willett WC, Stampfer MJ, Manson JE et al (1996) Coffee consumption and coronary heart disease in women. A ten-year follow-up. JAMA 275:458-462

19. Lopez-Garcia E, van Dam RM, Willett WC et al (2006) Coffee consumption and coronary heart disease in men and women: a prospective cohort study. Circulation 113:2045-2053

20. Lopez-Garcia E, van Dam RM, Li TY, Rodriguez-Artalejo F, Hu FB (2008) The relationship of coffee consumption with mortality. Ann Intern Med 148:904-914

21. Bidel S, Hu G, Qiao Q, Jousilahti P, Antikainen R, Tuomilehto J (2006) Coffee consumption and risk of total and cardiovascular mortality among patients with type 2 diabetes. Diabetologia 49:2618-2626

22. National Diabetes Data Group (1979) Classification and diagnosis of diabetes mellitus and other categories of glucose intolerance. Diabetes 28:1039-1057

23. Report of the Expert Committee on the Diagnosis and Classification of Diabetes Mellitus (1997) Diabetes Care 20:1183-1197 
24. Manson JE, Rimm EB, Stampfer MJ et al (1991) Physical activity and incidence of non-insulin-dependent diabetes mellitus in women. Lancet 338:774-778

25. Salazar-Martinez E, Willett WC, Ascherio A et al (2004) Coffee consumption and risk for type 2 diabetes mellitus. Ann Intern Med $140: 1-8$

26. Salvini S, Hunter DJ, Sampson L et al (1989) Food-based validation of a dietary questionnaire: the effects of week-to-week variation in food consumption. Int J Epidemiol 18:858-867

27. Rose GA BH (1982) Cardiovascular survey methods. WHO Monograph Series, No. 58. World Health Organization, Geneva

28. Walker AE, Robins M, Weinfeld FD (1981) The National Survey of Stroke. Clinical findings. Stroke 12:I13-44

29. Stampfer MJ, Willett WC, Speizer FE et al (1984) Test of the National Death Index. Am J Epidemiol 119:837-839

30. Hu FB, Stampfer MJ, Manson JE et al (1997) Dietary fat intake and the risk of coronary heart disease in women. N Engl J Med 337:1491-1499

31. Lopez-Garcia E, van Dam RM, Qi L, Hu FB (2006) Coffee consumption and markers of inflammation and endothelial dysfunction in healthy and diabetic women. Am J Clin Nutr 84:888-893

32. Willett WC, Sampson L, Stampfer MJ et al (1985) Reproducibility and validity of a semiquantitative food frequency questionnaire. Am J Epidemiol 122:51-65

33. Nathan DM, Meigs J, Singer de (1997) The epidemiology of cardiovascular disease in type 2 diabetes mellitus: how sweet it is ... or is it? Lancet 350(Suppl 1):SI4-9

34. Jee SH, He J, Appel LJ, Whelton PK, Suh I, Klag MJ (2001) Coffee consumption and serum lipids: a meta-analysis of randomized controlled clinical trials. Am J Epidemiol 153:353-362

35. van Dam RM (2006) Coffee and type 2 diabetes: from beans to beta-cells. Nutr Metab Cardiovasc Dis 16:69-77
36. Clifford MN (2000) Chlorogenic acid and other cinnamatesnature, occurrence, dietary burden, absorption and metabolism. J Sci Food Agric 80:1033-104

37. Shearer J, Farah A, de Paulis T, Bracy DP, Pencek RR, Graham TE (2003) Quinides of roasted coffee enhance insulin action in conscious rats. J Nutr 133:3529-3532

38. Johnston KL, Clifford MN, Morgan LM (2003) Coffee acutely modifies gastrointestinal hormone secretion and glucose tolerance in humans: glycemic effects of chlorogenic acid and caffeine. Am J Clin Nutr 78:728-733

39. Drucker DJ (1998) Glucagon-like peptides. Diabetes 47:159-169

40. Noordzij M, Uiterwaal CS, Arends LR, Kok FJ, Grobbee DE, Geleijnse JM (2005) Blood pressure response to chronic intake of coffee and caffeine: a meta-analysis of randomized controlled trials. J Hypertens 23:921-928

41. Urgert R, van Vliet T, Zock PL, Katan MB (2000) Heavy coffee consumption and plasma homocysteine: a randomized controlled trial in healthy volunteers. Am J Clin Nutr 72:1107-1110

42. Hamer M (2006) Coffee and health: explaining conflicting results in hypertension. J Hum Hypertens 20:909-912

43. van Dam RM (2008) Coffee Consumption and coronary heart disease: paradoxical effects on biological risk factors versus disease incidence. Clin Chem 54:1418-1420

44. Ulvik A, Vollset SE, Hoff G, Ueland PM (2008) Coffee consumption and circulating B-vitamins in healthy middle-aged men and women. Clin Chem 54:1489-1496

45. Ueland PM, Clarke R (2007) Homocysteine and cardiovascular risk: considering the evidence in the context of study design, folate fortification, and statistical power. Clin Chem 53:807-809

46. van Dam RM, Dekker JM, Nijpels G, Stehouwer CD, Bouter LM, Heine RJ (2004) Coffee consumption and incidence of impaired fasting glucose, impaired glucose tolerance, and type 2 diabetes: the Hoorn Study. Diabetologia 47:2152-2159 